\title{
Biogeochemical data from the Shamanka II Early Neolithic cemetery on southwest Baikal: Chronological and dietary patterns.
}

\author{
Andrzej W. Weber ${ }^{1,2}$ \\ Rick J. Schulting ${ }^{3}$ \\ Christopher Bronk Ramsey ${ }^{3}$ \\ Vladimir Ivanovich Bazaliiskii ${ }^{4}$ \\ ${ }^{1}$ Department of Anthropology, 13-15 H.M. Tory Building, University of Alberta, Edmonton, \\ Alberta, T6G 2H4, Canada, aweber@ualberta.ca \\ ${ }^{2}$ Laboratoire Méditerranéen de Préhistoire Europe Afrique (LAMPEA) - UMR 7269, Aix- \\ Marseille Université, 5 rue du Château de l'Horloge - B.P. 647, 13094 Aix-en-Provence Cedex 2, \\ France \\ ${ }^{3}$ Research Laboratory for Archaeology and the History of Art, Dyson Perrins Building, \\ University of Oxford, South Parks Road, Oxford, OX1 3QY, United Kingdom \\ ${ }^{4}$ Department of Archaeology and Ethnography, Irkutsk State University, Karl Marx Street 1, \\ Irkutsk 664003, Russia
}

\begin{abstract}
A data set of 116 AMS radiocarbon dates on human skeletal remains from an Early Neolithic (c. 7500-6700 cal BP) Shamanka II cemetery on Lake Baikal, Siberia, and associated carbon and nitrogen stable isotope values are analyzed for insights about site chronology and dietary variation of this group of hunter-gatherers. All dates are corrected for the Freshwater Reservoir Effect (FRE) according to the correction equations developed using paired radiocarbon dates on human and terrestrial faunal remains from the same graves (Bronk Ramsey et al., 2014; Schulting et al., 2014). Further examination of the data set provides the following main findings. First, it identified the presence of two phases of cemetery use at Shamanka II, each of quite different duration, separated by a relatively long period of disuse lasting as much as 300-550 years. Second, it demonstrated presence of four groups of people during the long Phase 1 each with a slightly different dietary pattern: three displaying a temporal change toward greater reliance on aquatic foods and one group, which apparently did not experience a diet shift. Third, the results show that all individuals from the short Phase 2 evince a clear chronological trend towards increased dietary contribution of aquatic food and that this pattern repeats closely one of the three trends present in Phase 1. While a generally similar chronological dietary trend has been found recently also among the Early Neolithic groups from the nearby Angara valley (Weber et. al., in press), the Shamanka II population appears to be much more diverse in dietary terms than its neighbours to the northeast.
\end{abstract}

Keywords: Cis-Baikal Siberia; Middle Holocene hunter-gatherers; radiocarbon dating; freshwater reservoir effect; cemetery chronology; dietary variation 


\section{INTRODUCTION}

Recent excavations at Shamanka II, directed by V.I. Bazaliiskii from Irkutsk State University as part of the Baikal Archaeology Project (BAP), have produced some of the most important developments for the middle Holocene archaeology of the Cis-Baikal region over the last 20-30 years. The academic significance of this material cannot be over-stated. Much has been written, both in Russian and English venues, about different aspects of the Early Neolithic (EN) Kitoi groups from the Angara valley, be it their origins and position in the cultural chronology of the region, mortuary traditions and ritual, craniology, demography, health and activity patterns, ancient DNA, or diet and subsistence. Unfortunately, the common drawback of all these studies is that they rarely discuss the results in the context of other Kitoi cemeteries from the region or in the context of other categories of archaeological materials from the same site.

For example, the eponymous Kitoi cemetery was published quickly after it was excavated in the 1880s (Vitkovskii 1982, 1989) and relatively much is known about grave inclusions, burial disposal and other aspects of the mortuary protocol at this site (Okladnikov 1950, 1974). However, since skeletal materials from this site have not been available for research for the last 50-80 years, they have not been studied in the same manner as those from Lokomotiv.

Consequently, no isotopic analyses have been done on the Kitoi collection with the exception of three skulls recently rediscovered in the Irkutsk Kraevedcheskii Muzei. However, due to the small number of samples these results are unlikely to make a significant impact (Weber et al., in press).

The research history of Lokomotiv, the largest EN cemetery in the Angara valley, contrasts with that of Kitoi. The materials excavated at Lokomotiv during the 1980s have been subjected to a comprehensive program of human bioarchaeological studies (radiocarbon dating, carbon, nitrogen and strontium isotopic analyses, health and activity patterns, and ancient DNA; c.f., Weber et al., 2010) in addition to the craniological studies conducted earlier on the skeletons recovered in the 1920s and 1950s (e.g., Debets, 1930; Gerasimov, 1955; Mamonova, 1973; 1983). To date, Lokomotiv remains the only EN sample from the Angara valley examined in such a way and this situation will not change any time soon. The problem with Lokomotiv is that the cemetery has not yet been published as a monograph and the level of empirical detail available in a few general accounts is inadequate to provide sufficient context for the relatively rich isotopic data. The other Kitoi cemeteries from the Angara valley (e.g., Ust'-Belaia or Galashikha), in addition to suffering from the same problems that lower the utility of the Kitoi and Lokomotiv collections, are affected either by their much smaller size or poor preservation of the skeletal materials.

These circumstances underscore the tremendous research value of Shamanka II. Its assemblage is much larger than that of Lokomotiv (although the latter has not been excavated in full), the grave goods are rich and diverse, their distribution across the graves and burials is quite variable, the cemetery has complex spatial organization, and the preservation condition of organic objects and of the human and faunal skeletal remains is generally very good. The skeletal materials have seen the same range of bioarchaeological and isotopic analyses as the Lokomotiv collection, all conducted concurrently with excavations at Shamanka or immediately after their completion in 2008. While much of this work is still in progress, monographic publications of this cemetery in English and Russian are currently in preparation and will cover many of these topics including detailed descriptions of grave assemblages.

Regarding chronological matters, a substantial freshwater reservoir effect (FRE) in radiocarbon age between terrestrial herbivores and aquatic fauna of Lake Baikal from the same 
archaeological layers has been recently identified in the materials from the campsite of SaganZaba II (Nomokonova et al., 2013). To define the extent to which this offset affects radiocarbon dates on human remains, a paired dating project was implemented. Forty-two pairs of human and terrestrial herbivore bone samples from a dozen or so middle Holocene cemeteries in the CisBaikal region, including Shamanka II, were selected. Two different approaches were used to develop an equation to correct the conventional human ${ }^{14} \mathrm{C}$ dates. Details are given in dedicated publications but it is important to emphasize that both, i.e. the Bayesian approach (Bronk Ramsey et al., 2014) and the linear regression method (Schulting et al., 2014; 2015) generated very similar correction equations. Bronk Ramsey and colleagues presented a regional correction model and Schulting and associates developed regional and micro-regional models of which the one for the Angara River combined with Southwest Baikal (including Shamanka II) is used in this paper.

The goal of this study is an examination of chronology and dietary variation at Shamanka II based on corrected radiocarbon dates and carbon and nitrogen stable isotope ratios. These two kinds of isotopic datasets are discussed together in the same paper rather than in separate studies because, as mentioned above, it has been demonstrated recently that in the environmental setting of Cis-Baikal, the vast majority of radiocarbon dates done on human skeletal remains are affected by the FRE. Since the diets of middle Holocene foragers in the region included spatially and temporally variable amounts and kinds of aquatic foods (Weber et al., 2011), conventional radiocarbon ages done on human skeletal remains are likely to overestimate their true age. The application of the resulting correction to the ${ }^{14} \mathrm{C}$-dated humans from Shamanka II provides a better understanding of the site's chronology and of dietary change over time.

The paper is divided into eight main sections. After these introductory notes, the Shamanka II cemetery is briefly described and the relevant sets of isotopic data examined in this study are presented. Next, we explain the methods of analysis and follow with assessment and discussion of the results. The discussion is organized into two sections: site chronology and dietary patterns, each divided further into sub-sections dedicated to general and more specific patterns. The paper ends with a summary of the findings and several conclusions of broader archaeological relevance.

\section{SHAMANKA II CEMETERY}

Shamanka II is located on a narrow peninsula (Shamanskii Mys) extending $\sim 600 \mathrm{~m}$ into the Kultuk Bay in the southwest corner of Lake Baikal (Figure 1; 51 $\left.41^{\prime} 54^{\prime \prime} \mathrm{N}, 103^{\circ} 42^{\prime} 11^{\prime \prime} \mathrm{E}\right)$ with five small rivers discharging into the lake in the vicinity, none longer than $\sim 25 \mathrm{~km}$ : Sliudianka, Pokhabikha, Talaia, Kultuchnaia and Medlianka. The cemetery was first discovered in 1962 when three graves were found exposed in the cliff of Shamanskii Mys. No further fieldwork was undertaken until one disturbed grave was found in 1996 and five more were rescued by A.V. Kharinskii and G.V. Turkin of the Irkutsk State Technical University from the collapsing cliff in 1998 and 1999 (Turkin and Kharinskii, 2004). From 2000 to 2008, the cemetery was subjected to large-area excavations directed by V.I. Bazaliiskii (Irkutsk State University) under the auspices of BAP. Excluding the graves documented in the 1960s, for which very little information is available, this fieldwork yielded $97 \mathrm{EN}$ and 12 Early Bronze Age (EBA) graves, as well as a single Late Bronze Age grave (Bazaliiskii and Weber, 2004; 2005). The EN graves contained the remains from a total of 155 individuals represented by skeletons ranging from nearly complete to those represented only by a few elements. Typological classification of the cemetery's EN component is unambiguous as it clearly belongs to the Kitoi mortuary tradition known archaeologically mostly along the Angara River (Okladnikov 1950, 1974, 1975, 1976; 
Bazaliiskii, 2010). Based on reservoir-corrected radiocarbon dating of human skeletal remains, the EN phase of Shamanka II dates from roughly from 7500 to $6700 \mathrm{cal} \mathrm{BP}$ (Weber et al., 2006; Weber et al., in press).

The graves were encountered about $20-25 \mathrm{~cm}$ below the modern surface. Grave-pits were originally dug from a layer of bright brown loam down to the limestone bedrock, reaching depths of 1.10 to $1.80 \mathrm{~m}$. Excavations produced no evidence for the presence of surface markers, such as stone or timber structures. The EN graves display characteristics of the Kitoi mortuary tradition, including supine body position, roughly $\mathrm{N}-\mathrm{S}$ orientation, multiple interments in the same grave-pit, head-to-toe arrangements, and the use of red ochre. This tradition is also reflected in the assortment of grave goods, among which the most diagnostic are the shanks of composite fishhooks, items of zoomorphic art, and marmot teeth. The distribution of grave goods is quite variable, ranging from no objects, or very few, to interments with hundreds of items. Many of the Kitoi graves at Shamanka II were extensively disturbed in prehistory and a large number of burials have substantial parts of their skeletons missing (Bazaliiskii, 2010) in a pattern generally similar to the one observed at the Ust'-Belaia cemetery on the Angara River (Georgievskaia, 1986). Many EN graves at Shamanka II contained single bones of individuals other than the main burials. Such skeletal elements are not considered separate interments and they are not included in the tally of EN burials.

The EN graves present a few discernible spatial arrangements (Figure 2). The most obvious are the two groups of graves in the north and south of the cemetery, referred to as the North and South Sectors. The North Sector is further divided into the Northwest and Southeast Clusters. Spatially these two units are not as distinct as the sectors but the distances separating the two clusters do appear somewhat greater than between the graves within each cluster. Also, there appears to be a void in grave distribution around the State Topographic Datum within the NW Cluster (Figure 2). This gap, however, is the result of lack of excavations there, a fenced off area with prohibited access. Fieldwork around this part of the cemetery actually confirmed the presence of a few graves there, which were left unexcavated. Therefore, the graves east of the Datum are considered part of the NW Cluster. Lastly, some graves are arranged side-by-side and these formations are referred to as rows. Rows are defined as a minimum of three graves arranged into one line with grave long axes roughly parallel one to another. Graves constructed outside of row formations are referred to as scattered. Twelve such rows have been identified and all, with one exception in the South Sector, run along the NW-SE axis (Figure 2).

\section{ISOTOPIC DATA}

Presently, three sets of isotopic data have been produced for Shamanka II. The first set is comprised of $\sim 180$ radiocarbon dates obtained from the Oxford Radiocarbon Accelerator Unit (ORAU), University of Oxford, UK, with stable carbon and nitrogen isotope ratios analyzed at the same time. This is the largest of the three sets of isotopic data available and forms the main focus of this paper. Collaboration with ORAU started in 2004 after the closure of the Isotrace Laboratory at the University of Toronto, Canada, and the majority of recorded individuals has now been dated at ORAU. With the exception of several dates included in the paired dating project (Bronk Ramsey et al., 2014; Schulting et al., 2014), the ORAU data have not been previously published. The ORAU radiocarbon and stable isotope data available for EN individuals from the Angara valley $(\mathrm{n}=50)$, presented here only in graphs, provide additional context for the assessment of the Shamanka II results (Weber et al., in press). 
The second set of isotopic data includes carbon and nitrogen stable isotope ratios produced in collaboration with scholars from the University of Calgary, Canada, and consists of two subsets. At the time when radiocarbon dating was being done at Isotrace, carbon and nitrogen isotopes were measured by Dr. M.A. Katzenberg producing results for 69 individuals excavated between 1999 and 2004. The second subset includes carbon and nitrogen isotope values representing 21 individuals analyzed by Dr. A. Waters-Rist, currently of Leiden University, for her dissertation research focusing on infant diets and weaning practices and, therefore, this topic is not discussed here. All isotopic data obtained from Calgary have already been published (Waters-Rist et al., 2011; Weber et al., 2011). Since essentially all isotopic measurements produced for Shamanka II in Calgary have been repeated in Oxford, the Calgary results are not employed in this study. However, the previously published Calgary carbon and nitrogen stable isotope data for the EBA groups from the Little Sea micro-region located in the middle of the northwest coast of Lake Baikal are used for comparison (Weber et al., 2011).

The third set of results available for Shamanka II involves radiocarbon dates obtained at Isotrace for 46 burials excavated between 1999 and 2003, all published by Weber et al. (2006). Although Isotrace did not report stable isotope measurements, it would still be possible to correct these dates for the FRE using the stable isotope results from Calgary, enabling their inclusion in the analysis alongside the ORAU dates. However, aside from some difficulties related to the fact that in a number of instances different skeletal elements were measured in the labs, the ORAU and Isotrace dates appear to be not particularly compatible. Currently, there are 31 Shamanka II individuals dated at both laboratories (Table 1; Weber at al. 2006: Table 2) but in 11 cases these pairs do not pass the $\chi^{2}$ test of the R_Combine function in OxCal 4.2 (Ward and Wilson 1978). ${ }^{1}$ In 10 instances the Isotrace date is significantly younger than the ORAU date. This difference may relate to the improved removal of contaminants provided by the use of $30 \mathrm{kD}$ ultra-filters at Oxford (Brock et al., 2010). As all Shamanka II individuals dated at Isotrace have been since reanalyzed at ORAU, the Isotrace dates are omitted from analysis.

In sum, of 155 identifiable EN Shamanka II individuals 138 (89\%) have been dated at ORAU while 17 have never been submitted due to the lack of suitable material for dating. All sex and age determinations of the individuals examined and this study have been provided by Dr. Angela Lieverse, University of Saskatchewan, Canada, as part of the ongoing investigation of the Shamanka II collection of human remains.

\section{METHODS}

\subsection{Laboratory methods}

All radiocarbon dating was done at the Oxford Radiocarbon Accelerator Unit (ORAU), with stable carbon and nitrogen isotope measurements made on the same ultra-filtered collagen preparation used for dating (Brock et al., 2010) (Supplement 1). Stable isotope analyses were done in either triplicate or duplicate on each sample, with the averages reported here, relative to the internationally accepted standards VPDB for $\delta^{13} \mathrm{C}$ and AIR for $\delta^{15} \mathrm{~N}$. A subset of 55 samples were run with a two-point calibration using in-house cow and seal collagen standards, in turn referenced to international standards. For a small number of individuals $(n=3)$, only single runs were possible due to small sample size. These have been retained, as there was a strong correlation ( $r>0.9$ for both isotopes) between the samples measured in duplicate with the twopoint calibration and single tests done separately without the two-point calibration (see also

\footnotetext{
${ }^{1}$ The group of 31 dates from Isotrace includes only those with collagen yields $\geq 1 \%$.
} 
Schulting et al., 2014). Analytical precision for $\delta^{13} \mathrm{C}$ and $\delta^{15} \mathrm{~N}$ is \pm 0.2 and $\pm 0.3 \%$, respectively. Collagen quality was assessed primarily by $\mathrm{C} / \mathrm{N}$ ratios, supplemented by collagen yields, $\% \mathrm{~N}$ and \%C (DeNiro 1985; van Klinken 1999). No results were rejected on the basis of these collagen quality criteria.

\subsection{Correction of the freshwater reservoir effect}

In the present study we use the following regression model developed by Schulting et al. (2014) for the Southwest Baikal and Angara micro-regions:

$$
Y=-1388.8522+125.4503\left(\delta^{15} \mathrm{~N}\right)^{2} \text {, where }
$$

$Y$ is the predicted offset between the conventional (atmospheric) ${ }^{14} \mathrm{C}$ ages of paired human-faunal measurements from the same grave, and $\delta^{15} \mathrm{~N}$ is the nitrogen stable isotope value for the human. The corrected ${ }^{14} \mathrm{C}$ age of an individual is then obtained by subtracting the offset value $(Y)$ from the conventional radiocarbon age while the standard deviation of the corrected date is calculated according to the following equation:

$$
\sqrt{ }\left(\text { s.d. }{ }^{2}+S^{2}\right) \text {, where }
$$

s.d. is the error associated with the conventional ${ }^{14} \mathrm{C}$ measurement and $\mathrm{S}$ is the standard deviation of residuals from the linear regression, 64.1 in this case. The linear regression equation appears to work well for the Southwest Baikal and Angara micro-regions combined, accounting for $\sim 80 \%$ of the variation in human-faunal ${ }^{14} \mathrm{C}$ offsets $\left(\mathrm{r}^{2}=0.814, p<0.000\right)$ (Schulting et al., 2014: Table 4).

Since the regression equation relies on the $\delta^{15} \mathrm{~N}$ value, it is not possible to apply it to those individuals whose $\delta^{15} \mathrm{~N}$ is affected, in addition to the aquatic diet, by other factors such as breastfeeding. While it would be possible to subtract from the given isotopic value the assumed trophic level effect of 3-5\%, it is not clear whether the entire value should be applied. It would be unrealistic to expect lack of variation in the onset and nature of weaning (Weber et al., 2002; Waters-Rist et al., 2011) and subtract a fixed number depending on the age of an infant, for example $3 \%$ from $\delta^{15} \mathrm{~N}$ value of a 1-year-old, $2 \%$ from a 2-year-old etc. Besides, skeletal age determinations of young children and the 3-5\%o trophic level fractionation carry their own uncertainties (e.g., Raynard and Turros, 2015). While this issue will be revisited in the future, it was decided that for this study we would not correct the conventional radiocarbon dates for young children whose $\delta^{15} \mathrm{~N}$ signatures are likely affected by breastfeeding. Based on our current knowledge about the onset of weaning among Cis-Baikal's middle Holocene foragers (WatersRist et al., 2011), this problem applies to 21 individuals assessed to be 5 years old and younger. Thus, this group is omitted from analysis and the isotopic results are not published in this paper. It must be kept in mind, however, that in individual cases some residual nursing effect might still be present in the bone collagen of children older than 5 years. In these cases, the elevated $\delta^{15} \mathrm{~N}$ value may over-correct the radiocarbon determination, resulting in a corrected date that is too young. Since in the present dataset there is only one child aged 5-7 years old, this is not a significant problem (Table 1).

It can be argued that the animal dates from the paired dating program could be preferentially used over the corrected human bone dates, thus avoiding altogether the FRE for these burials. However, for consistency with graves that do not contain animal remains, we apply the

\footnotetext{
${ }^{2}$ Although regression equations are normally presented with one or two decimal places, here we show four as provided by the regression analysis and as employed in the calculation of the corrected dates. Rounding was done only at the very completion of the entire procedure rather than at each step.
} 
regression equations for the FRE to all dated humans over the age of 5 years, including those in the paired dating program from which the corrections were developed.

\subsection{Conventions}

With a few different kinds of dates referred to in the paper, the following terms and acronyms are used to ensure clarity:

(1) The ${ }^{14} \mathrm{C}$ determinations provided by ORAU are referred to as conventional, uncorrected, or simply ${ }^{14} \mathrm{C}$ or radiocarbon dates and are presented in years BP; and

(2) ${ }^{14} \mathrm{C}$ dates transformed with the linear regression equation are referred to as corrected ${ }^{14} \mathrm{C}$ dates and are also presented in years BP.

Only the corrected ${ }^{14} \mathrm{C}$ dates are calibrated and analyzed further using Bayesian statistics, generating two additional age estimates:

(3) Each corrected ${ }^{14} \mathrm{C}$ date has a counterpart in the mean $(\mu)$ with standard deviation $(\sigma)$ and median cal BP age of the highest posterior distribution (HPD) interval (Table 1); it is the means and associated standard deviations that are principally used for further quantitative analysis and graphs;

(4) Groups of dates (events) are used to calculate durations of relevant archaeological intervals such as periods or phases of cemetery use and their boundaries. These are presented in the text and graphs generated by OxCal as HPD intervals in cal BP years, Table 2 and Figure 3 providing the $68.2 \%$ and $95.4 \%$ confidence levels and probability distributions. Following accepted practice, all modelled dates are presented in italics.

\subsection{Combining radiocarbon dates}

The entire set of ORAU radiocarbon determinations from the Shamanka II cemetery used in this study, each with complete chemical data and relevant archaeological information, is presented in Table 1 . The total number of dates was actually much higher than the 116 individuals included in the analysis because in a number of cases the same burial was dated multiple times (Supplement 1). In most instances, this is a product of ORAU's routine internal checks involving repeat measurements. In other cases, the same sample or a different one from the same individual was submitted for analysis for additional checks, in some cases prompted by apparently questionable results obtained on the first measurement. Such multiple dates representing the same individual (Supplement 1) were combined in the following manner:

1. Method 1: Dates on the same sample and on the same collagen extraction (indicated by the same "P" number) were first combined using an error-weighted mean as implemented in the R_Combine function of OxCal and next the resulting product was FRE-corrected. Dates on the same sample but on different extractions (indicated by different "P" numbers) were processed in the same fashion.

2. Method 2: Dates on two different samples (i.e., skeletal elements) were first FREcorrected to account for the potentially slightly different turnover rates in the examined elements and next the resulting products were combined using the R_Combine function in OxCal.

3. Method 3: Sets of dates (usually three or more), which included repeats on the same and different sample, were transformed using a combination of Methods 1 and 2.

4. The use of Methods 2 and 3 meant that in 14 instances we did not generate a combined radiocarbon determination before FRE correction and the difference between the 
corrected and conventional age is an average of the results provided by Method 1. In these cases only the FRE-corrected dates were combined before calibration.

5. The chemical data, including the $\delta^{13} \mathrm{C}$ and $\delta^{15} \mathrm{~N}$ values, were averaged over such multiple runs to supply the data for the FRE correction (Table 1).

To combine the multiple dates available for some individuals, we chose to combine before rather than after calibration (i.e., using the R_Combine method of OxCal rather than the Combine method). The Combine method in OxCal allows combination of dates derived from different methods or from radiocarbon dates with different known age offsets; it assumes that each date and calibration provides completely independent information. In general, R_Combine method gives wider errors because it accommodates the fact that the uncertainty associated with the calibration of the different combined dates is highly correlated; it is intended for dates where the true age of the samples dated is the same within the resolution of the calibration curve (here effectively decadal). Although in this case there may be slight offsets on the dates on the same individual due to bone collagen turnover differences, these differences are likely to be small and in any case are not quantified. For this reason we conclude that combination before calibration (using R_Combine) is more appropriate and also more conservative, generating wider calendar range estimates.

After the removal of results identified as problematic, all remaining multiple ${ }^{14} \mathrm{C}$ determinations for the same individual were combined as described above in all 25 instances passing the $\chi^{2}$ test (Ward and Wilson 1978; Table 1).

\subsection{Quantitative methods}

Selection and implementation of quantitative analytical methods depends on research goals and on the kind of data analyzed. As mentioned, the main goals of this study are two: (1) examination of Shamanka II chronology based on the evidence of conventional radiocarbon dates corrected for FRE; and (2) assessment of dietary variation, temporal and otherwise, of the Shamanka II group of people using the same radiocarbon evidence and the associated carbon and nitrogen stable isotope ratios.

\subsubsection{Chronology}

The first goal is approached mainly with Bayesian modelling done in OxCal 4.2.4 based on the IntCal-13 dataset (Reimer et al., 2013; Bronk Ramsey, 2014). We are aware that the Shamanka II set of radiocarbon dates lends itself to a variety of modeling approaches both in terms of units of analysis and functions used. In addition to the entire cemetery, its main spatial units (sectors and clusters) and rows of graves are also viable units of analysis. These, however, are not the only useful lines of investigation. For example, there are graves with multiple individuals arranged vertically on different layers, in some cases separated by a layer of sediment, as well as some graves that disturb one another. Additionally, changes in the temporal distribution of mortuary traits could also be examined. While some of this work is already in progress, it is clear that delving into even a few of these options in sufficient detail would be well beyond the scope of this study.

Bayesian modeling is guided by the following prior knowledge and assumptions about the nature of the mortuary record in question:

1) So far, no methods utilizing typology of grave goods and other aspects of the mortuary protocol to arrange this materials into a chronological sequence have been developed for 
any of the middle Holocene mortuary traditions documented in the Cis-Baikal region, including the EN Kitoi to which Shamanka II belongs.

Further, there are no empirical or theoretical grounds to assess:

2) The tempo (e.g., abrupt vs. gradual) of the development and termination of the Kitoi mortuary tradition as a whole in the Angara and Southwest Baikal micro-regions or of individual Kitoi cemeteries of any size.

3) Population models for the Kitoi groups (e.g., constant population or population growth $>$ peak $>$ decline, etc.) and resulting human burial deposition rates micro-regionally or within each larger cemetery.

Considering the above, two OxCal models were constructed. The first one builds on OxCal's default assumption of a uniform distribution (i.e., deposition rate) of dated events (i.e., human burials) within archaeological periods or phases and thus invokes potentially relatively abrupt transitions, such as the start and end of cemetery use. The uniform distribution model employs the following commands:

- Sequence to order events within a phase (group of events);

- Boundary to model start and end of various groups (phases) of events;

- Span to define temporal span of the dated events; and

- Interval to define phase durations.

However, the prior knowledge presented above suggests that a model accounting for variable deposition rates of the dated events may be a more realistic approach. It is the trapezoidal distribution model that was developed recently specifically to accommodate these conditions in OxCal 4.2.4 (Lee and Bronk Ramsey, 2012). The trapezoidal model accommodates the following: (1) that many archaeological processes are regional- and population-level changes which, as such, are usually gradual, although the tempo may vary, and cumulative rather than abrupt and transformative; and (2) that cemetery commencement and abandonment may also be gradual events.

The trapezoidal model, in addition to the functions listed above, requires that the Boundary command be used in conjunction with the following three functions:

- Transition to allow a Boundary to have a non-instantaneous transition period as this function creates trapezoid-shaped distributions; and

- Start and End to find the start and end of a Boundary with a gradual transition period, respectively.

The input files for the uniform and trapezoidal models are included as Supplements 2 and 3. Corrected radiocarbon dates for the Angara micro-region and its largest EN cemeteryLokomotiv - have been built into the same OxCal file as independent models to facilitate presentation of results in the same graph. The corrected dates in all three datasets were first assessed for any discontinuities and based on this the Shamanka II set was divided into two nonabutting phases. The models were populated with the corrected dates from Table 1 for Shamanka II while for the Angara micro-region and the Lokomotiv cemetery the corrected ORAU dates from Weber et al., in press (Table 1) were used. The two models, with all records sorted by the corrected radiocarbon date, were then submitted to OxCal for analysis. Since the results from the uniform and trapezoidal models are very similar one to another (which in itself suggests relatively rapid commencement and cessation of the cemetery's use for burial), the subsequent analysis, graphs and discussion is based on the results from the trapezoidal distribution model. Table 1 displays the results (mean and median HPD cal BP dates) of the trapezoidal model only 
while Table 2 summarizes both for comparison. Graphs plotting mean HPD cal BP dates divided into various units of analysis complement the Bayesian modelling.

\subsubsection{Diet}

Our second goal involves examination of dietary variation with three specific objectives in mind: (1) general assessment of the EN diet at Shamanka II in the broader regional context; (2) intrasite comparison between various units of analysis defined based on spatial criteria and skeletal sex determinations; and (3) search for changes in diet over time. The first two objectives employ the same suit of statistical tests assisted by graphs. Non-parametric Kruskal-Wallis H-test with with Dunn's post-hoc test and Mann-Whitney U-test are used because in most cases our datasets do not meet the condition of normal distribution for each of the independent variables as per Shapiro-Wilk tests for normality (Shapiro and Wilk, 1965). This line of examination is limited to those units of analysis that are large enough to produce meaningful results. Descriptive statistics are provided in Tables 3 and 4.

Assessment of chronological changes in diet uses mainly Pearson product-moment correlation coefficients (PCC) between the temporal parameters (i.e., conventional ${ }^{14} \mathrm{C}$ dates, corrected, dates, means and medians of HPD cal BP intervals) and the stable isotope signatures $\left(\delta^{13} \mathrm{C}\right.$ and $\left.\delta^{15} \mathrm{~N}\right)$ - the critical variables in this examination. The mean and median HPD cal BP dates were provided by the results from both models: uniform and trapezoidal distributions. Since in all cases the PCC results were essentially the same, only correlations with the mean HPD cal BP dates from the trapezium distribution model are reported in the paper. Scatter plots are used for illustrative purposes and potential identification of non-linear relationships between relevant variables. The entire statistical analysis was conducted using IBM SPSS Statistics v. 23.

\section{DATA ASSESSMENT}

Only one individual had to be excluded from analysis because of problematic radiocarbon dates. Two different samples from individual SHA_2003.026.05 ${ }^{3}$ produced dates in the range of 5550 years BP that were consistent with one another but entirely inconsistent with the dates for three other skeletons from the same grave (Table 1) and also substantially younger than the rest of the dates from Shamanka II and generally much later than the Kitoi mortuary tradition as a whole. These two dates are not included in Table 1 and Supplement 1. Since Grave 26 was substantially disturbed in the past, with all individuals interred there represented by variably incomplete and largely disarticulated skeletons, it is probable that individual No. 26.05 represents a much later intrusion, in fact falling within the very poorly known and elusive - in terms of its mortuary tradition-Middle Neolithic (Weber et al., 2010; Weber et al., in press). Unfortunately, the disturbed nature of the grave does not help shed much light on the matter, but it is interesting to see the re-use of the location of an EN cemetery at this time, even if, as it seems, for only a single interment.

Individual SHA_2004.042.02 attracts attention due to its low $\delta^{15} \mathrm{~N}$ value of $10.5 \%$ o (Table 1, Supplement 1). While such a value is not outside the range seen in Cis-Baikal, it is clearly an outlier within the EN Shamanka II and Angara datasets. However, it is unlikely that this is due to measurement error as two different samples were run at Oxford, both giving essentially the same result, while a previous analysis on yet another sample at the University of Calgary produced a

\footnotetext{
${ }^{3}$ Each individual excavated at Shamanka II was assigned a master identification number, which includes the following information: site's mnemonic name (SHA), excavation year (e.g., 2003), grave number (e.g., 026), and individual number in graves with more than one interment (e.g., 05).
} 
value of $11.1 \%$, the lowest in the Calgary dataset (Weber et al., 2011: Table 9). The $\delta^{15} \mathrm{~N}$ signature suggests a diet with a much lower contribution of aquatic food and, together with the $\delta^{13} \mathrm{C}$ measurement of $-17.7 \%$, implies an origin different than either the Kultuk Bay or the Angara River. If so, the regression formula developed for these micro-regions may not be applicable to this individual. Given that the low $\delta^{15} \mathrm{~N}$ value suggests minimal contribution of Baikal fish in the diet of this individual, the FRE has little effect on the conventional ${ }^{14} \mathrm{C}$ date, leaving this burial the oldest by a large margin within the entire Shamanka II dataset and almost 1000 years older than the other interment from the same grave (SHA_2004.042.01, Table 1). While the upper body of individual No. 42.02 was disturbed, most elements with the exception of the cranium were still present and the legs preserved their extended burial position. Also, there is nothing in the archaeological context, including the grave goods, that would suggest such an old date for this individual (Weber et al., in press). We can offer no explanation for this discrepancy, other than the possibility that a different reservoir correction applies to this case, though admittedly the low $\delta^{15} \mathrm{~N}$ value does not suggest the consumption of much aquatic protein of whatever origin. Conversely, the relatively elevated $\delta^{13} \mathrm{C}$ result of $-17.7 \%$ may be viewed as evidence for the consumption of a certain amount of Baikal inshore fish, rather than a purely terrestrial diet, leaving the interpretation of the diet of this individual uncertain. While the radiocarbon date for No. 42.02 has been corrected (Table 1), we believe that it should be excluded from the chronological analysis. However, this individual is included in the analysis of non-chronological dietary patterns, as its outlying $\delta^{15} \mathrm{~N}$ value does not violate the assumptions of the non-parametric tests used in this examination.

Since the PCC analysis is quite sensitive to outliers, all datasets suitable for examination of chronological trends were screened using the outlier labeling technique (Hoaglin et al., 1986; Hoaglin and Iglewicz, 1987). Only one individual, No. 42.02, failed this test due to its very low $\delta^{15} \mathrm{~N}$ value of $10.5 \%$. This individual, however, was already excluded from the chronological analysis because the applied correction equation likely is not valid in this case.

In sum, in addition to the 21 young children removed from this examination earlier, the following two individuals and associated isotopic data are excluded from various aspects of the analysis:

- No. 26.05, both sets of radiocarbon and stable isotope data are excluded from all analyses; and

- No. 42.02, the radiocarbon date and stable isotope results are excluded from the chronological analysis only (i.e., Bayesian modelling and PCC tests).

Thus, the examination of Shamanka II chronology and dietary patterns employs 115 (74\%) and $116(75 \%)$ individuals, respectively.

\section{DISCUSSION: CHRONOLOGY}

The focus of this section is on the general chronology of the Shamanka II cemetery, its continuity of use, spatial patterns, and temporal distribution of female and male burials, interment of subadults, and graves with multiple burials.

\subsection{General chronology}

Excluding No. 42.02 from the chronological analysis, the remaining 115 corrected ${ }^{14} \mathrm{C}$ dates from Shamanka II range from $6898 \pm 73$ years BP (SHA_2005.025.03) to 5771 \pm 74 years BP (SHA_2005.026.02) (Table 1). On average, the entire corrected sequence of dates is 466 years younger than the uncorrected series with the lowest and highest corrections being 135 years for 
SHA_2003.026.02 (6355 \pm 73 years BP) and 725 years for SHA_2006.014.01 (6179 \pm 74 years BP), respectively (Table 1$)$.

Table 2 presents the results of Bayesian modelling for Shamanka II using the trapezoidal and uniform distributions. Included in the table are the HPD intervals and the means of the distributions for the start, end, and duration of Phases 1 and 2 at Shamanka II as well as for the length of the gap between them. The intervals are presented at the $68.2 \%$ and $95.4 \%$ probability intervals. Probability distributions and mean ages are displayed in Figure 3. Results for the Angara valley as a whole and for the Lokomotiv cemetery are included for comparison. The outcomes of both models are generally very similar one to another, which indicates the robustness of the conclusions irrespective of model choice and, as mentioned earlier, suggests relatively rapid commencement and abandonment of burial practices at Shamanka II. The agreement indices $\left(\mathrm{A}_{\text {model }}\right)$ for the Shamanka's trapezoidal and uniform distribution models are 80.9 and 61.2 , respectively.

The Shamanka II modelled sequence generally parallels the series of mean $\mathrm{HPD}{ }^{14} \mathrm{C}$ dates currently available for the Angara valley including Lokomotiv. However, the entire Shamanka II sequence appears to start $\sim 80$ earlier and end $\sim 270$ years later than the Angara (Table 2, Figure 3 ). The offset regarding the EN lower boundary in these two micro-regions is relatively small and may be attributable to the difference in sample sizes (115 vs. 50) and the fact that in the Angara valley there are still many EN burials to be dated, including a few dozen from Lokomotiv. In contrast, the difference regarding the upper boundary is quite large and may reflect real differences in longevity of EN mortuary traditions in these two areas. We will reassess the modelled start and end ranges when more dates for EN burials from the Angara valley become available.

\subsection{Discontinuity of use}

The temporal distribution of the corrected dates (Table 2) shows a gap of 97 years between $6147 \pm 74$ BP (SHA_2001.012) and 6050 \pm 52 BP (SHA_2004.049.01) but in terms of the modelled mean HPD dates (Table 2) the gap expands to 418 years between $7217 \pm 42 \mathrm{cal} \mathrm{BP}$ (SHA_2001.012) and 6799 \pm 45 cal BP (SHA_2004.049.01). The relevant portion of the middle Holocene calibration curve features a few flat or even reversed sections, the product of variation in ${ }^{14} \mathrm{C} /{ }^{12} \mathrm{C}$ ratio in the Earth's atmosphere. However, while the gap partly coincides with one such section on the calibration curve visible roughly between 7150 and 7050 cal BP (Bronk Ramsey, 2014; Reimer et al., 2013), Bayesian modelling confirms that the discontinuity is real rather than a product of the variation in the abundance of atmospheric ${ }^{14} \mathrm{C}$. This provides initial evidence for the presence of two intervals of cemetery use at Shamanka II: a longer Phase 1 ( $283 \pm 45$ years) and a much shorter Phase 2 (142 \pm 87 years) separated by a considerable gap of $399 \pm 59$ years (Table 2). Such discontinuity is visible neither in the Angara valley taken as a whole, nor in the dates from Lokomotiv (Figure 3). The dates from the Angara valley appear to fill much of the gap at Shamanka II, which on its own is an interesting pattern the significance of which will require comprehensive examination of additional archaeological and biological data.

A reasonable question to ask is whether the group of 38 individuals not accounted for in the chronological analysis (21 young children removed from examination and 17 burials - mostly adults - without suitable material for dating) could bridge this discontinuity. For the following reasons it seems unlikely that the groups of 21 young children alone would be sufficient to do so. First, adults would be clearly required for the population to function normally. Second, it would be rather unusual for the cemetery to be used during this time for interment of very young 
children preferentially over everyone else. And third, we notice, that the four Phase 1 subadults do not cluster chronologically and, therefore, expect a similar temporal distribution of the remaining 21 young children. While it is possible that the adults could fill in the gap, it seems reasonable to believe that the overall sample size of the dated burials (74\%) is representative enough of the chronological patterns. Furthermore, the presence of two phases is supported by additional evidence presented later in the paper and this includes changes in how the cemetery was used during Phase 2 relative to Phase 1 (see sections 6.4 and 6.5). Thus, even if the undated individuals eventually bridge the gap, the chronological model, instead of two discontinuous phases, will have two abutting intervals.

\subsection{Spatial patterns}

Assuming, then, two phases of cemetery use, the North and South Sectors appear to have been used concurrently during both phases, starting and ending around the same time (Figure 4a). Dividing the North Sector further into NW and SE Clusters, however arbitrary this may seem, gives three main spatial units of analysis and all three appear to have been used concurrently with one another from beginning to end of both phases (Figure 4a). No additional discontinuities are identified. Based on how the graves are arranged within the cemetery two other units of analysis can be identified - graves in rows and scattered graves - and these two groups can be further divided according to which sector or cluster they belong to. Keeping in mind that some rows are not as clearly identifiable as others, they are, nevertheless, a practical independent unit of analysis worth further examination. This line of investigation at the EBA Khuzhir-Nuge XIV cemetery, located in the Little Sea micro-region of Cis-Baikal, yielded some interesting insights about mobility, migrations, diet and subsistence strategies (Weber and Goriunova, 2013).

Overall, 12 such rows (A-L) have been identified at Shamanka II (Figure 2) and all have been dated to some extent. Disposal in graves in rows and in scattered graves apparently was practiced at roughly the same rate throughout the entire life of the cemetery (Figure 4b). However, all 12 rows were established in Phase 1 and no new rows were formed during Phase 2. Some rows seem to have been used more or less continuously only during Phase 1 (e.g., rows C, D and E) but some (e.g., rows B, F, G, I, J and K) saw new interments added during Phase 2 after a long period of disuse (Figure 4b). With the exception of individual SHA_2003.030 (Row J), disposed of in a single-burial grave built in Phase 2, the remaining seven new row interments were all placed in graves already established in Phase 1 . Row K, the only one featuring a SWNE orientation, does not stand out chronologically from the other 11 rows, all running NW-SE.

A few observations mentioned in this section relate to the fact that the excavations at Shamanka II produced no evidence of any structures marking the EN graves on the surface at the time they were built. For example, arrangement of graves into sectors, clusters and rows, rare disturbance of one grave by another among the scattered graves, addition of new interments into existing graves after a considerable amount of time would all, at least intuitively, require some sort of surface markers to facilitate such arrangements and activities.

\subsection{Sex, age, and graves with multiple interments}

Age and sex groups seem to exhibit some chronological variation across the use-span of Shamanka II. Recall, however, that 21 young children are excluded from this analysis because their conventional ${ }^{14} \mathrm{C}$ dates have not been corrected for the FRE. The male and female categories also include probable males and probable females. Relative to males, females and subadults aged between 7 and 15 years old are substantially under-represented in both phases 
(Figure 5a) although, keep in mind that only 17 individuals in the analyzed dataset belong to Phase 2. Furthermore, there are no statistically significant differences between the two phases in proportions of males vs. females and adults vs. subadults.

The number of burials per grave at Shamanka II varies from one to five with the majority of graves $(\sim 80 \%)$ containing single or double burials (Figure $5 \mathrm{~b}-\mathrm{c}$, Table 1$)$. Graves with single and double interments display a pattern of continuous usage throughout the life of the cemetery.

Graves with three or more interments, however, display a different pattern. All graves with four or five burials were built exclusively in Phase 1, if not toward its first half (Figure 5c).

Interments from graves with three individuals show the pattern mentioned earlier: after these graves were built during Phase 1, new burials were added to them much later during Phase 2. Note, however, that no graves with more than three interments were constructed in Phase 2, as observed above. A few graves with two burials also appear to have the first individual interred during Phase 1 and the second, much later during Phase 2 (Figure 5c). Lastly, Phase 1 saw only one grave with two burials (No. 64) built during this time (Figure 5c).

\subsection{Summary of general chronology}

On the present evidence, the two-phase model of cemetery use seems reasonably well supported by the radiocarbon evidence, i.e., the distribution of the mean HPD ages. Examining, as this paper does, only a limited number of spatial, demographic, and mortuary variables there are some subtle changes in how Shamanka II was used during Phase 2 relative to Phase 1: (1) no graves with more than three individuals and only one with two were built during Phase 2 ; (2) no new rows of graves were established during Phase 2; and (3) most row burials dating to Phase 2 represent secondary use of graves already arranged into rows during Phase 1 . Certainly, this matter will have to be examined in more detail using a broad range of mortuary characteristics and grave goods, a focus of work already in progress. Thus, the most interesting aspects of the modelled chronology of Shamanka II are (Table 2):

- The long duration (Interval) of Phase $1(399 \pm 59)$ relative to rather short Phase $2(142 \pm 87$ years); and

- The substantial gap between Phase 1 and Phase 2 (399 \pm 59 years), perhaps even longer than the duration of Phase 1.

These findings, i.e., the presence of two phases of cemetery use and the long gap between them, immediately raise questions regarding the causes of the break in cemetery use and the reasons behind the reuse of the cemetery much later. Without, at the minimum, detailed assessment of mortuary variability within each phase, which is much beyond the scope of this paper, any insights in this regard would be rather premature. Nevertheless, we will return briefly to the matter in the Summary and Conclusions section.

\section{DISCUSSION: DIETARY PATTERNS}

\subsection{Diet of the Early Neolithic Shamanka II people}

Graphically, the Shamanka II dataset occupies the space between the EN individuals from the Angara valley, which display somewhat higher $\delta^{13} \mathrm{C}$ values, and the EBA foragers with the Game-Fish-Seal (GFS) diet from the Little Sea, which show somewhat lower $\delta^{13} \mathrm{C}$ measurements (Figure 6, Table 4; c.f. Weber et al., 2011: Figure 4). Although the distribution of Shamanka II $\delta^{13} \mathrm{C}$ values overlaps slightly with the other two distributions, the differences between them are statistically significant while the $\delta^{15} \mathrm{~N}$ datasets are statistically the same (Kruskal-Wallis H-test, df $=2, \delta^{13} \mathrm{C}, p<0.000 ; \delta^{15} \mathrm{~N}, p=0.484$; Table 3 ). With regard to the $\delta^{13} \mathrm{C}$ datasets, in the post- 
hoc comparison all three groups differ from one another: Kruskal-Wallis $\mathrm{H}$ test with Dunn's post-hoc test, $\delta^{13} \mathrm{C}$, SHA $-16.3 \pm 0.7$, Angara $-15.2 \pm 0.4$, Little Sea GFS $-18.1 \pm 0.7, p<0.000$ in all three pairwise comparisons). This implies that at the population level the main vector of differences between these three samples is not in the quantity of the aquatic contribution to the dietary protein (reflected in $\delta^{15} \mathrm{~N}$ ) but rather in its kind, which is quite variable along the $\delta^{13} \mathrm{C}$ scale. This variation largely depends on the rates of photosynthesis in the local aquatic habitat (Yoshii et al., 1999; Weber et al., 2011).

Also, the distribution ranges for the GFS group from the Little Sea and Shamanka II are quite similar while the EN Angara sample displays a more clustered distribution (Figure 6, Table 3). Shamanka II shows a range of $3.1 \%$ (from -18.0 to $-14.9 \%$ ) for $\delta^{13} \mathrm{C}$ and $6.4 \%$ (from 10.5 to $16.9 \%$ ) for $\delta^{15} \mathrm{~N}$ while the respective ranges for the EN Angara sample are $1.9 \%$ (from -16.3 to $-14.4 \%$ ) and $2.4 \%$ (from 13.9 to $16.3 \%$ ). Excluding burial No. 42.02 from these calculations, the range of $\delta^{15} \mathrm{~N}$ values at Shamanka II is still approximately twice as large as on the Angara ( $4.8 \%$, from 12.1 to $16.9 \%$ ). This is interesting because the Angara sample is comprised of several sites separated by a distance of up to $\sim 250 \mathrm{~km}$ while Southwest Baikal is represented by only one site. The obvious question, then, concerns the sources and causes of dietary variation at Shamanka II.

Since contribution of plant foods to the diet of all middle Holocene hunter-gatherers in the Baikal regions appears to have been minimal (Katzenberg et al., 1999; 2010; Weber et al., 2002; 2011) and since the terrestrial herbivores in the Baikal region show limited variability in their bone collagen $\delta^{13} \mathrm{C}$ and $\delta^{15} \mathrm{~N}$ ratios (Weber et al., 2011: Tables 2 and 3), it is clear that the pattern of individual variation at Shamanka II is best explicable in terms of variable consumption of freshwater foods, a situation similar to that of the EBA groups in the Little Sea micro-region (Weber et al., 2011; Weber and Goriunova, 2013). In the Baikal region there are three relevant groups of freshwater resources. The first includes various Baikal fishes and the lake's endemic seal (Phoca sibirica), which together cover a wide range in $\delta^{13} \mathrm{C}$ and $\delta^{15} \mathrm{~N}$ values from about $-25 \%$ to $-10 \%$ and from roughly $10 \%$ to $16 \%$, respectively (Weber et al., 2011: Table 5). The second group are the fishes from the small and medium size immature rivers, which are expected to show limited variation in $\delta^{13} \mathrm{C}$ signals similar to the values documented on the Upper Lena (approximately from $-27 \%$ to $-24 \%$; Weber et al., 2011: Table 5)). The third group comprises the fishes of the Angara River. Unfortunately, due to the three dams built between Baikal and Bratsk in the mid-twentieth century, there are no useful modern fish stable isotope data available for this ecosystem and measurements on archaeological specimens are likewise lacking. However, based on our understanding of the region's stable isotope ecology, we expect $\delta^{13} \mathrm{C}$ values there to be much higher than on the Upper Lena but not as high as in the shallows of Lake Baikal. The $\delta^{15} \mathrm{~N}$ values of the riverine fishes should be similar to those in the Baikal system, though perhaps without the full range of trophic levels, not least because the seal-the top predator in Lake Baikal — does not enter the rivers.

As it is not unrealistic to expect that the people from Shamanka II would have had access to all three groups of freshwater food resources (the most distant being the Angara, some $75 \mathrm{~km}$ to the northeast), the next question to ask is about aspects of human behaviour that would account for the observed isotopic variation. For example, extensive sharing, equal access to different kinds of fisheries, and mobility covering roughly the same area over extended time intervals would be expected to result in limited stable isotope variation, which is not what we see in the Shamanka II dataset. Thus, it is useful to consider the Baikal fishery in a little more detail. 
The matter regards the relative contribution of three kinds of aquatic food from the lake: the inshore shallow water fishes, the pelagic omul' (Coregonus autumnalis migratorius), and the Baikal seal. A previous analysis concluded that in the Baikal waters around Shamanka II the fishes were expected to show “... a less variable $\delta^{13} \mathrm{C}$ signal than the more diverse bathymetry of the Little Sea..." and that it was the consumption of the seal that best accounted for the wide range of $\delta^{13} \mathrm{C}$ measurements in the Shamanka II humans (Weber et al., 2011: 242). However, not fully appreciated at the time was the fact that in the shallows of the Kultuk Bay one would actually expect a mix of fishes from all three coastal habitats of Lake Baikal: shallow cove-andlagoon $(<5 \mathrm{~m})$, littoral $(5-20 \mathrm{~m})$, and sub-littoral $(>20 \mathrm{~m})$, all three transitioning there gradually from one to the other (Weber et al., 2002: Table 1). Considered together, such fishes as roach (Rutilus rutilus lacustris), dace (Leuciscus leuciscus baicalensis), ide (Leuciscus idus), lenok (Brachymystax lenok), whitefish (Coregonus lavaretus baicalensis), pike (Esox lucius), perch (Perca fluviatilis) and black and white graylings (Thymallus arcticus baicalensis and Thymallus arcticus baicalensis brevipinnis) cover a range of about $10 \%$ in bone collagen $\delta^{13} \mathrm{C}$ values from roughly $-20 \%$ o to $-10 \%$ (Weber et al., 2011). Although the work conducted on archaeofauna from camp sites in the Little Sea micro-region (Losey et al., 2008; Nomokonova et al., 2011; 2015) indicates that all middle Holocene hunter-gatherers lacked the capacity for fishing the pelagic waters of Baikal, one should not rule out altogether at least some dietary contribution from the omul'. While the inshore shallows are not its preferred habitat, it is not entirely unlikely that the omul', with $\delta^{13} \mathrm{C}$ values in the $-25.0 \%$ to $-22.0 \%$ range, thus about $2 \%$ more negative than the Baikal seal (Weber et al., 2011:Table 5), could not had been harvested there in small numbers during the colder seasons of the year (spring and autumn) along with the other species. In much larger numbers, however, it could be harvested in the Selenga River delta some $230 \mathrm{~km}$ to the east, entered by the omul' for spawning runs (Kozhov, 1963; 1972). Moreover, further away from the shore Baikal seal with $\delta^{13} \mathrm{C}$ measurements around $-22 \%$ would be available in winter and spring (Nomokonova et al., 2013; Weber et al., 1998). All these resources considered together cover a wide range of $\delta^{13} \mathrm{C}$ values from $-25.0 \%$ to $-10.0 \%$.

However, in order for this ecological variation to be reflected in human isotopic values, some kind of sorting mechanism would have had to be in place, such as differential access to resources or differential sharing once they were acquired. While the presence of such differential access to and sharing of food resources is, of course, a possibility, a more parsimonious explanation is that those buried at Shamanka II constitute a more heterogeneous group in terms of their places of origin, and hence with respect to their diets, than the Angara groups. In addition to more variation in the $\delta^{13} \mathrm{C}$ values of local freshwater food relative to the Angara fishes, it may therefore be that individuals at Shamanka II carry isotopic signatures of other fisheries such as the lower Selenga River to the east, the middle Irkut River to the west (Weber et al., 2011) and the Angara to the northeast. In the absence of fish measurements from these river systems, or human measurements from the Selenga and Irkut, the details of their isotopic ecology remain unclear, but the proposed scenario is not implausible. No associated large EN campsite has been found on the peninsula on which Shamanka II is located, nor have any such sites been found in the surrounding area. This is not to say, of course, that they do not exist, only that the presently available evidence suggests that the cemetery may have been used by a range of surrounding groups. We return to this matter later in the paper.

In sum then, while the above observations generally are in agreement with the previous assessment of the Shamanka II diet (Weber et al., 2011), the current examination suggests a few revisions regarding the role of seal and open water fishes in the diet. This is not to discount the 
contribution of the seal entirely, merely to make two additional points. First, that perhaps the seal did not contribute as much to the diet as previously suggested, an observation consistent with the analysis of the stable isotope data in the context of the corrected radiocarbon dates as discussed later in the paper. And second, that given the wide range of human $\delta^{13} \mathrm{C}$ values, the relative contribution of the different kinds of fishes, from the local shallows and other rivers as well as the Baikal seal was apparently quite variable.

\subsection{Chronological trends}

Turning attention to temporal matters, all PCC calculations were conducted including and excluding the seven subadults, both datasets producing essentially the same results. Therefore, only the former are reported in the following analysis (Table 5). As a whole, the set of 115 mean HPD dates and stable isotope values available for Shamanka II shows a small although statistically significant negative correlation between the mean HPD dates and $\delta^{15} \mathrm{~N}$ values $(r=$ $-0.196, p=0.036, \mathrm{n}=115)$ while on the Angara the correlation is much stronger $(r=-0.711, p$ $<0.000, \mathrm{n}=50$; Weber et al., in press). As the mean HPD dates become younger on the Angara, the $\delta^{15} \mathrm{~N}$ values become higher. Prior to the FRE correction, at Shamanka II these variables show no correlation $(r=-0.096, p=0.306, \mathrm{n}=115)$ while on the Angara the correlation remains negative although moderate rather than strong and is still statistically significant $(r=-0.402, p=$ $0.004, \mathrm{n}=49$; Weber et al., in press).

Calculating PCC for the two phases at Shamanka II separately shows a strong and statistically significant negative correlation within Phase $1(r=-0.595, p<0.000, \mathrm{n}=98)$ and an even stronger negative correlation within Phase $2(r=-0.902, p<0.000, \mathrm{n}=17)$, closer to and exceeding the values observed on the Angara, respectively. That the correlation within the entire dataset at Shamanka II is much weaker than within each phase separately is explained partly by the fact that at the beginning of Phase 2 the $\delta^{15} \mathrm{~N}$ values appear to return to a similar level as at the beginning of Phase 1 (Figure 7) and partly by the fact that the nature of temporal dietary variation in Phase 1 seems to be quite different from Phase 2 as discussed below. Plotting the mean HPD dates against $\delta^{15} \mathrm{~N}$ values shows the trends for the Angara and Shamanka II Phase 2 quite clearly, while the pattern for Phase 1 is more variable (Figure 7).

Of the four datasets discussed above (i.e., Shamanka II overall, Shamanka II Phase 1 and Phase 2 separately and EN Angara) only one shows statistically significant, however weak, correlation between mean HPD dates and $\delta^{13} \mathrm{C}$ values (Phase 1: $r=-0.211, p=0.037, \mathrm{n}=98$ ), a fact that may be informative in its own right (Table 5). Namely, since the Baikal seals display bone collagen $\delta^{13} \mathrm{C}$ values around -22\%o (Weber et al., 2011), if the main source of aquatic food were the seal rather than the inshore fishes, one would expect a positive correlation between these two variables and a concomitant negative correlation with $\delta^{15} \mathrm{~N}$. This is because if the consumption of the seal increased over time, the $\delta^{13} \mathrm{C}$ signatures in human consumers should become more negative, and the $\delta^{15} \mathrm{~N}$ values should increase, but this is not what is seen in the Shamanka II dataset.

If this line of reasoning is correct, the negative correlation between mean HPD dates and $\delta^{15} \mathrm{~N}$ values and the lack of strong positive correlation with $\delta^{13} \mathrm{C}$ measurements at Shamanka II generally indicates a trend of increased consumption of the fishes available in the shallows of the Kultuk Bay. Additional support comes from the Angara valley, where the stable isotope results and modern seal ecology both suggest no dietary intake of the Baikal seal, yet the correlations between the three relevant variables show the same pattern as at Shamanka II. This suggests that the dietary role of the seal at Shamanka II was insignificant and that most of the variation in $\delta^{13} \mathrm{C}$ 
values is likely attributable to the variation present in the Baikal fishes available locally in the inshore waters of the Kultuk Bay and in the nearby rivers (e.g., Irkut).

The observation that the Shamanka II sample is less homogeneous than the Angara group is further supported by the patterns emerging once Phase 1 individuals are divided into analytical sub-units based on spatial criteria (Table 5, Figure 7). More specifically, correlations between mean HPD dates and $\delta^{15} \mathrm{~N}$ values within the NW Cluster and the South Sector are moderate and weak, respectively, and statistically insignificant (NW Cluster, $r=-0.231, p=0.314, \mathrm{n}=21$; South Sector, $r=-0.204, p=0.466, \mathrm{n}=15)$ while individuals from the SE Cluster show a strong negative correlation $(r=-0.743, p<0.000, \mathrm{n}=62)$. A closer look at the SE Cluster reveals a further difference between burials in rows of graves $\left(\delta^{15} \mathrm{~N}, r=-0.801, p<0.000, \mathrm{n}=47\right)$ and burials in scattered graves $\left(\delta^{15} \mathrm{~N}, r=-0.281, p=0.310, \mathrm{n}=15\right)$. Interestingly, the row burials also show a moderate negative correlation between mean HPD dates and $\delta^{13} \mathrm{C}$ measurements $(r=$ $-0.395, p=0.006, \mathrm{n}=47$ ) while the scattered burials display a strong positive correlation with $\delta^{13} \mathrm{C}(r=0.686, p=0.005, \mathrm{n}=15)$ and, as mentioned, no correlation with $\delta^{15} \mathrm{~N}$. Continued examination of the SE Cluster burials in rows suggests that both sexes drive this relationship equally (males: $\delta^{13} \mathrm{C}, r=-0.349, p=0.069, \mathrm{n}=28 ; \delta^{15} \mathrm{~N}, r=-0.863, p<0.000, \mathrm{n}=28$ vs. females: $\left.\delta^{13} \mathrm{C}, r=-0.546, p=0.054, \mathrm{n}=13 ; \delta^{15} \mathrm{~N}, r=-0.829, p=0.000, \mathrm{n}=13\right)$.

Within the framework explained earlier, the negative correlations between the mean HPD dates and both stable isotopes observed for the SE Cluster row burials corroborate one another in the sense that both indicate temporal trends toward an increased dietary contribution of shallow water fishes. A different pattern, however, is seen among the SE Cluster's scattered burials, which show a strong positive correlation between the mean HPD dates and $\delta^{13} \mathrm{C}$ values and no correlation with $\delta^{15} \mathrm{~N}$ measurements. If the cause of the lower $\delta^{13} \mathrm{C}$ values were the procurement of Baikal seals, one would also expect correspondingly higher $\delta^{15} \mathrm{~N}$ values in the SE Cluster's scattered burials. However, the data do not show this relationship, possibly implying the exploitation of two different fisheries by these groups. Thus, it seems reasonable to suggest that the main source of low $\delta^{13} \mathrm{C}$ values in the SE Cluster's scattered burials is neither the Baikal seal nor the pelagic omul' harvested coincidentally with the shallow water fishes in the Kultuk Bay but some other recourses. Two options can be considered here: one is the omul' intercepted during its spawning runs in the Selenga River and the other the fishes of immature rivers such as the middle Irkut or other similar watercourse, both expected to display overlapping range of $\delta^{13} \mathrm{C}$ values from -27.0 to $-22.0 \%$. The consumption of such fishes would make the $\delta^{13} \mathrm{C}$ measurements as negative as those resulting from dietary intake of the Baikal seal without necessarily increasing the $\delta^{15} \mathrm{~N}$ signatures relative to the fishes from the Baikal shallows.

The burials in scattered graves from the SE Cluster are all actually part of a larger unit of analysis defined on the basis of the same criteria - the North Sector's scattered burials. The results of PCC analysis for all scattered burials from the North Sector are interesting as they match the pattern displayed by the SE Cluster's scattered burials alone: $\delta^{13} \mathrm{C}, r=0.685, p=$ $0.001, \mathrm{n}=19$ and $\left.\delta^{15} \mathrm{~N}, r=-0.192, p=0.430, \mathrm{n}=19\right)$. The South Sector's scattered burials show a similar negative relationship for $\delta^{13} \mathrm{C}(r=-0.704, p=0.184, \mathrm{n}=5)$, and a stronger but also negative relationship for $\delta^{15} \mathrm{~N}(r=-0.855, p=0.065, \mathrm{n}=5)$; that neither attains statistical significance is clearly due to the small sample size, since the correlation coefficients are high. This may suggest the presence of yet another dietary trend at Shamanka II, somewhat different from the one identified for the burials in rows of graves in the SE Cluster and scattered graves of the North Sector. To be consistent with the line of reasoning followed in this analysis, this 
temporal trend would have to be interpreted as increased concomitant reliance on the inshore fishes from the Kultuk Bay, or some other similar fishery, and the Baikal seal.

It seems, therefore, that the strongest evidence for a dietary trend toward greater reliance on fishing comes from the individuals interred in graves arranged into rows in the SE Cluster of Shamanka II and in this case the source of fish seems to be the shallows of the Kultuk Bay. Equally well-supported dietary trend regards the group of scattered burials from the North Sector but in this case a fishery different from the Kultuk Bay or the Angara River was involved. The data also suggest that the diets of males and females equally account for either chronological trend. The row burials from the South Sector and from the NW Cluster reveal no temporal patterning between the mean HPD dates and the carbon and nitrogen stable isotope values.

It appears then that the distinction between the NW and SE Clusters within the North Sector of the cemetery is not as arbitrary as it may appear based on the spatial criteria alone.

Furthermore, the isotopic data suggest that arrangement of graves into rows and scattered formations has quite meaningful socio-cultural rationale involving at least different diets and foraging ranges. All this considered together further supports the earlier observation about substantial spatial and chronological heterogeneity in the behaviour of the groups contributing to the Shamanka II cemetery, a point to which will we will return again later.

Examination of carbon and nitrogen stable isotope results by phase does not provide any new insights (Figure 8a). According to the Mann-Whitney U-test there are no statistically significant differences between Phase 1 and Phase 2 (regardless of whether or not No. 42.02 is included in Phase 1). The main difference is in the range of the stable isotope values which seems to be consistent with the fact that, in terms of radiocarbon and stable isotope measurements, Phase 2 looks much more homogeneous relative to Phase 1 .

Lastly, it is useful to comment briefly on some of the correlations between the uncorrected radiocarbon dates and stable isotope measurements at Shamanka II:

- $\quad$ Phase 1: $\delta^{13} \mathrm{C}, r=0.043, p=0.671 ; \delta^{15} \mathrm{~N}, r=-0.196, p=0.053, \mathrm{n}=98$;

- Phase 2: $\delta^{13} \mathrm{C}, r=-0.405, p=0.106 ; \delta^{15} \mathrm{~N}, r=0.376, p=0.137, \mathrm{n}=17$; and

- Phase $1 \mathrm{SE}$ Cluster row burials: $\delta^{13} \mathrm{C}, r=0.022, p=0.886 ; \delta^{15} \mathrm{~N}, r=-0.129, p=0.389, \mathrm{n}$ $=47$.

As mentioned earlier, these results would, at best, suggest a weak chronological trend toward increased reliance on aquatic food during Phase 1 as a whole and no discernible trends during Phase 2 or Phase 1 SE Cluster row burials. Overall, such picture is quite different from what the examination of stable isotope data in the context of the FRE-corrected dates clearly indicates.

\subsection{Spatial patterns and females vs. males}

The small number of individuals assigned to Phase $2(\mathrm{n}=17)$ limits further analysis to Phase 1 ( $\mathrm{n}=99$, including burial No. 42.02). The examination of non-temporal dietary patterns within Phase 1 is restricted to those units of analysis that are large enough to warrant comparison. In terms of spatial organization this relates to sectors and clusters and also graves arranged into rows vs. those scattered throughout the cemetery. Demographic comparison is limited to adult females vs. males.

There is some evidence of spatial patterning in the isotopic results for Phase 1 (Table 3 ). The North Sector individuals have slightly but statistically significantly higher $\delta^{15} \mathrm{~N}$ values $(14.8 \pm 0.83 \%, \mathrm{n}=83)$ than those of the South Sector $(14.0 \pm 1.35 \%, \mathrm{n}=16$, Mann-Whitney Utest, $p=0.004)$. The North Sector also has slightly higher $\delta^{13} \mathrm{C}$ values $(-16.2 \pm 0.70, \mathrm{n}=83)$ than the South Sector $(-16.8 \pm 0.49, \mathrm{n}=16$, Mann-Whitney U-test, $p=0.002)$. In a three-way 
comparison of the South Sector and the North Sector's constituent NW and SE Clusters, there is a statistically significant difference in both $\delta^{13} \mathrm{C}$ and $\delta^{15} \mathrm{~N}$ measurements (Kruskal-Wallis H-test with Dunn's post-hoc test) only between the SE Cluster (higher values) and the South Sector (lower values): $\delta^{13} \mathrm{C},-16.1 \pm 0.72 \%, \mathrm{n}=62$ vs. $-16.8 \pm 0.49 \%, \mathrm{n}=16, p<0.000 ; \delta^{15} \mathrm{~N}$ $14.9 \pm 0.87 \%$, $\mathrm{n}=62$ vs. $14.0 \pm 1.35 \%, \mathrm{n}=16, p=0.003$. No statistically significant differences were found in the following comparisons: females vs. males in any of the main spatial units, burials in rows vs. scattered graves in general, and, interestingly, between SE Cluster's row burials and North Sector's scattered burials (Figure 9).

\subsection{Summary of stable isotope results}

Overall then, in dietary terms, there appear to be five groups of people buried at Shamanka II. Four of them coexisted with one another during Phase 1 (Figure 7), with three groups experiencing temporal change in diet and one whose diet did not change over time. Interestingly, these differences are not visible, once the temporal variable is removed from analysis. An overview of our findings regarding these five groups follows.

The dietary trend in the first group is based on the increased over time consumption of the fishes from the shallows of the Kultuk Bay. This trend is seen in 47 individuals interred in graves arranged into rows in the cemetery's SE Cluster.

Diachronic dietary change in the second group appears to involve the increased consumption of fishes characterized by $\delta^{13} \mathrm{C}$ values narrower in range and much lower than in the lake's inshore waters. At Shamanka II, individuals belonging to this group were buried only in scattered graves of the North Sector (i.e., NW Cluster and SE Cluster, $n=19$ ). Since the Angara, where $\delta^{13} \mathrm{C}$ values are expected to be equally narrow in range but much higher, is an unlikely candidate for the location of this fishery we suggested two other places: the lower Selenga River to the east with its seasonal omul' runs from Baikal or the middle Irkut to the west. However, it is not clear which fits the available data better. Not much is known about the Selenga fishery except that the Baikal's omul' would show $\delta^{13} \mathrm{C}$ values in the -25.0 to $-22.0 \%$ range (Weber et. al., 2011: Table 5); Unfortunately, no stable isotope data are available for the river's other fishes. It is unclear whether the seasonally available omul' would bias the stable isotope results away from those characteristic of the local fishes, which would be harvestable during much of the year. The presence of a large EN cemetery at Fofanovo near the mouth of the Selenga may speak in favour of the connections between the Kultuk Bay and the lower Selenga River (Figure 1).

Another possibility for the location of the fishery reflected in the low $\delta^{13} \mathrm{C}$ measurements of this group of people is the middle Irkut valley to the west of Lake Baikal. Archaeological finds dating typologically to the middle Holocene in general and the EN in specific have been reported from the area for some time, although no campsites or cemeteries are known so far (Weber et al., in press). Whatever the case, lower Selenga or middle Irkut, much work will be needed to demonstrate or refute these links empirically.

A small group of individuals from the scattered graves of the South Sector show some evidence of the increased consumption of inshore fishes and the Baikal seal. Even though the relationships between the relevant isotopic results in this case have not achieved statistical significance due to the small sample size $(n=5)$, we believe that this observation should not be dismissed for it is consistent with the general pattern of substantial dietary diversity documented for the entire Shamanka II dataset. The fourth group, displaying no evidence of a dietary shift over time, includes all remaining Phase 1 individuals (i.e., from graves in rows), from the NW Cluster $(n=17)$ and South Sector of the cemetery $(n=10$; excluding No. 42.02). 
And the fifth group refers to the 17 adults from Phase 2 regardless of spatial location (sectors and clusters) or grave formation (rows or scattered). This group shows evidence of a temporal dietary shift that is, perhaps, the most clearly identifiable based on the available data. The trend appears to be similar in nature to that noted for the SE Cluster adults from graves in rows in that it is based on the increased consumption of fishes from the surrounding shallows of the Kultuk Bay. The difference, however, is that the individuals from Phase 2 are not limited in distribution to any specific spatial unit or grave formation, which is unlike the other two trends and in particular the trend displayed by the SE Cluster row burials.

In sum then, with four different patterns, Phase 1 seems to be rather diverse in terms of dietary choices pursued while Phase 2 appears to be quite homogeneous. Even more interesting is that Phase 1 presents much more isotopic - and by inference dietary - diversity than the entire Angara EN sample which is nearly as homogenous as Phase 2 at Shamanka II. Phase 2 individuals also appear to repeat the dietary trend first displayed during Phase 1 by those interred in the SE Cluster row burials.

Although space is limited, these patterns invite at least some comments regarding the sociocultural significance of this diversity. A good place to start is to assess what makes Shamanka II a different EN cemetery from those known from elsewhere around Cis-Baikal. Since nearly all middle-Holocene cemeteries, EN or otherwise, are located close to a good fishery of some kind, the placement of Shamanka II may have something to do with its unique topographical setting. As mentioned, the cemetery is located on a high peninsula extending far into the lake, a prominent feature highly visible from the entire coast of the Kultuk Bay. While there are many comparable landmarks around Lake Baikal, most with names derived from the word shaman, this is the only such location along the coast of the Kultuk Bay and even beyond. Furthermore, none of the Kitoi cemeteries known from the Angara feature equally spectacular settings, all being instead established on river terraces (e.g., Kitoi, Ust'-Belaia and Galashikha) or, at best, on a high promontory (Lokomotiv). Fofanovo, the only known EN cemetery on the Selenga River, is also located on a river terrace (Gerasimov and Chernykh, 1975). The main reason for this is, obviously, that such topographically prominent places are generally absent from these river valleys.

The only cemetery in the region with a similar or perhaps even more spectacular location is Shamanskii Mys on Ol'khon Island in the Little Sea micro-region (Figure 1). It is a relatively small cemetery with only one EN grave, three LN and seven EBA graves (Konopatskii, 1982); however, its ceremonial significance and use has been implicated on a few occasions (Konopatskii, 1982, Okladnikov and Konopatskii 1974-1975; Weber et al., 2002; Shepard et al., n.d.) as supported by the following evidence: unique body position of the EN burial furnished with wooden stakes, sheets of birch bark, shanks of Kitoi composite fishhooks (very rare in the Little Sea area) and two dog skeletons; inclusion of rare grave goods as well as dog and seal skeletons in the LN but mostly in the EBA graves; and a large number of animal bones (mostly deer and seal) recovered from the area encircled by the graves. The ceremonial, other than mortuary, significance of the Shamanskii Mys is further emphasized by its high visibility, limited access as well as the presence of a dramatic rock with a cave protruding from the lake in the nearest vicinity - overall one of the most visually powerful places around entire Lake Baikal.

At Shamanka II, to keep the matter short, the most obvious aspects of the mortuary ritual signifying the unusual ceremonial status of the cemetery are bear remains (skulls, baculae etc.) and rituals - not known from any other EN cemetery in the region (Bazaliiskii, 2010; Losey et al., 2013) and frequent grave disturbances known, as mentioned above, from only one other 
location-Ust'-Belaia. With the exception of the rock with the cave, Shamanka II displays similar topographic properties as the Shamanskii Mys cemetery on Ol'khon Island. In this context it seems justified to suggest that Shamanka II could have served during the EN as an important mortuary and ceremonial gathering point attracting groups from other micro-regions such as the Angara valley, middle Irkut, and the lower Selenga River, in addition, of course, to being a focal point of the local Kitoi groups. This paper leaves little room to develop and test these ideas further but it clearly underscores the importance of dedicated investigation of temporal patterns in the distribution of mortuary characteristics and the employment of other isotopic tracers such as strontium isotope ratios to address the place of origin of those interred in the cemetery, both studies being in progress.

\section{SUMMARY AND CONCLUSIONS}

This is the sixth paper in the series of studies examining the FRE in the Cis-Baikal region and its impact on the chronology and subsistence adaptations of middle Holocene foraging groups. In the first one we identified that presence of the FRE in the Baikal ecosystem (Nomokonova et al., 2013). In the next three we demonstrated the influence of the FRE on ${ }^{14} \mathrm{C}$-dated human remains in the Cis-Baikal ecosystem and developed equations to correct for it (Bronk Ramsey et al., 2014; Schulting et al., 2014; 2015), while in the most recent paper (Weber et al., in press) and in this study we make use of these new developments. More specifically, when applied to a dataset of radiocarbon and carbon and nitrogen stable isotope results from the EN Shamanka II cemetery, the approach allowed two main new insights with regard to culture change and diversity. The first is the identification of two phases of cemetery use, and the second is the discovery of a substantial amount of variation in terms of dietary trends experienced by the apparently different groups of people buried at Shamanka II.

The identification of two phases of cemetery use at Shamanka II is novel and important but its significance is unclear. Without knowing whether this is a local pattern or one reflecting a broader regional development, any scenario proposed at this point would be highly speculative. The data from the Angara and Lokomotiv do not show a similar discontinuity but there are scores of burials to date from entire valley before this can be demonstrated with any confidence. One possible way of explaining Phase 2 at Shamanka II could be that it represents an attempt to reinstate the EN Kitoi system after its dissolution - for whatever reason —on the Angara. Southwest Baikal could be one of a few places where such attempts were made.

Discovery of the dietary trends at Shamanka II, and on the Angara, is perhaps even more important. Despite the extensive program of radiocarbon dating applied to middle Holocene foragers in the Baikal region, the temporal dynamic has been thus far limited. Without the FRE correction the dietary trends are either weak, as for the Phase 1 patterns, or absent, as for Phase 2 and the SE Cluster row burials. As mentioned early in the paper, much bioarchaeological work has been completed on middle Holocene human skeletal remains from the Cis-Baikal region and this has provided the foundation of our understanding of many aspects of diet and mobility. However, these studies, individually and together, have been unsuccessful in defining any kind of temporal changes within relevant units of analysis such as archaeological period (e.g., EN, Late Neolithic or EBA), micro-region (e.g., Angara, Southwest Baikal, Little Sea, and Upper Lena) or specific cemetery (e.g., Shamanka II, Lokomotiv, Ust'-Ida, or Khuzhir-Nuge XIV). Simply put, all our findings thus far regarded patterns resulting from comparison between these large units of analysis rather than smaller units within them. Consequently, the discovery of a chronological trend toward greater reliance on aquatic food of some sort during the EN is an 
extremely promising finding for it expands our analytical perspective from comparison between these large units to examination of temporal changes in foraging behaviour within them..

However, equally interesting and important is that one group apparently did not change its diet over the same course of time.

The processes leading to the formation and eventual dissolution of the EN Kitoi socioeconomic system are still poorly understood (Weber and Bettinger, 2010) and the identification of a dietary trend toward increased reliance on fishing affecting much of the Angara and Southwest Baikal EN Kitoi population clearly may be implicated. It is reasonable to expect that an increased reliance on fishing could be related to the depletion of high-ranked terrestrial game resources such as moose, red deer and roe deer. Progressive concentration of the EN population in a few favoured areas could have lead to overhunting, the fisheries being more resistant to depletion. While fishing could perhaps support most of the dietary needs of these hunter-gatherers for an extended period of time, some level of hunting would still be needed to provide other materials such as hides and sinew for clothes and shelter and bone for tools. Without data from campsites with sufficient temporal resolution, which, unfortunately, so far are lacking, it will be difficult to test this scenario empirically.

The results of this study are also encouraging in the sense that many more patterns are likely to emerge once the isotopic data are comprehensively examined in the context of the mortuary information available for Shamanka II. New patterns are also expected to appear with addition of the strontium isotope system to the range of analytical methods applied to Shamanka II individuals. Additional useful investigation avenues will include the bear rituals (Losey et al., 2013), grave disturbances, Bayesian analysis of other temporal patterns including the tempo of cemetery use, all in addition to the more traditional examination of distribution of grave goods and other elements of mortuary treatment.

Lastly, the results are also promising in the sense that equivalent or different patternshowever difficult to isolate empirically - may be present within not only the EN Lokomotiv cemetery, but also the Late Neolithic and EBA periods. Lokomotiv and Ust'-Ida (Late Neolithic ad EBA), are equally rich and differentiated along similar lines as Shamanka II and KhuzhirNuge XIV (e.g., dietary diversity and spatial organization) and are likely to produce many revealing insights. All this represents the beginning of a major shift in current research on middle Holocene foragers in the Baikal region from a focus on how the relevant hunter-gatherer strategies functioned to how they changed over time.

\section{ACKNOWLEDGEMENTS}

We owe our thanks to the members of the Baikal Archaeology Project for their enthusiastic involvement in the fieldwork in Russia and implementation of various laboratory analyses over the last 25 years, and to the Social Sciences and Humanities Research Council of Canada for its continuous financial support (Major Collaborative Research Initiative grants Nos. 410-20001000, 412-2005-1004, and 412-2011-1001). We are extremely thankful to Drs. A. Bayliss, British Heritage, and J. Meadows, Christian-Albrechts-Universität zu Kiel, for their very thorough reading of a different but similar paper and for many useful ideas for improvements to both studies and for a number of stimulating comments and suggestions regarding the broader problem of dealing with the freshwater reservoir effect in the Cis-Baikal region and making the best possible use of our data. We are equally grateful for the constructive criticism provided by the two anonymous reviewers. Our very cordial thanks go also to Ms. Erin Jessup, BAP, 
University of Alberta, for the assistance with the preparation of this paper and particularly for organizing and cross-checking the large body of archaeological, biological, and geochemical data used in this paper. While we are most grateful for all this help, all shortcomings are of our own responsibility. Lastly, and most importantly, this research would not have been possible without the continuous support of Irkutsk State University in Russia and our numerous Russian friends who never hesitated to help our project in the most generous and imaginative ways. 


\section{REFERENCES}

Bazaliiskii, V.I., 2010. Mesolithic and Neolithic mortuary complexes in the Baikal region of Siberia. In: Weber, A.W., Katzenberg, M.A., Schurr, T. (Eds.), Prehistoric Hunter-Gatherers of the Baikal Region, Siberia: Bioarchaeological Studies of Past Lifeways. University of Pennsylvania Museum of Archaeology and Anthropology, Philadelphia, pp. 51-86.

Bazaliiskii, V. I., and A. W. Weber. 2004. Pogrebal'nye kompleksy epokhi rannego neolita na mogil'nike Shamanka II. In: A.P. Derevianko and V.I. Molodin (Eds.), Problemy arkheologii, etnografii, antropologii Sibiri i sopredel'nykh territorii, Vol. 10(1. Novosibirsk: Institut arkheologii i etnografii SO RAN), pp. 33-40. [In Russian]

Bazaliiskii, V. I., and A. W. Weber. 2005. Raskopki pogrebal'nykh kompleksov epokhi rannego neolita na mogil'nike Shamanka II v 2005 g. In: A.P. Derevianko and V.I. Molodin (Eds.), Problemy arkheologii, etnografii, antropologii Sibiri i sopredel'nykh territorii, Vol. 11(1).

Novosibirsk: Institut arkheologii i etnografii SO RAN, pp. 16-21. [In Russian]

Brock F, Higham TFG, Ditchfield P, Bronk Ramsey C. 2010. Current pretreatment methods for

AMS radiocarbon dating at the Oxford Radiocarbon Accelerator Unit (ORAU). Radiocarbon 52(1), 102-12.

Bronk Ramsey, C., Schulting, R.J., Goriunova, O.I., Bazaliiskii, V.I., Weber A.W. 2014. Analyzing radiocarbon reservoir offsets through stable nitrogen isotopes and Bayesian modeling: A case study using paired human and faunal remains from the Cis-Baikal region, Siberia. Radiocarbon 56 (2), 1-11.

Bronk Ramsey, C. 2009. Bayesian analysis of radiocarbon dates. Radiocarbon 51 (1), 337-60.

Bronk Ramsey, C. 2014. OxCal 4.2.4. https://c14.arch.ox.ac.uk/.

Debets, G. F. 1930. Opyt vydeleniia kul'turnykh kompleksov v neolite Pribaikal'ia. Izvestiia Assots. NII pri FMF MGU 3(2a), 151-69. [In Russian]

DeNiro, M.J. 1985. Post-mortem preservation and alteration of in vivo bone collagen isotope ratios in relation to palaeodietary reconstruction. Nature 317, 806-9.

Hoaglin, D.C., Iglewicz, B. 1987. Fine-Tuning Some Resistant Rules for Outlier Labeling. Journal of the American Statistical Association 82 (400), 1147-1149.

Hoaglin, D.C., Iglewicz, B., Tukey, J.W. 1986. Performance of some resistant rules for outlier Labeling. Journal of the American Statistical Association 81 (396), 991-999.

Georgievskaia, G.M. 1989 Kitoiskaia kul'tura Pribaikal'ia. Nauka, Novosibirsk. [In Russian]

Gerasimov, M. M. 1955. Vosstanovlenie litsa po cherepu: Sovremennyi i iskopaemyi chelovek. Trudy Instituta etnografii im. N. N. Miklukho-Maklaia 28. Novosibirsk: Nauka. [In Russian]

Gerasimov, M.M., Chernykh, E.N. 1975. Raskopki fofanovskogo mogil'nika v 1959 g. In: A. M. Mandel'shtam (Ed.), Pervobytnaia arkheologiia Sibiri. Nauka, Leningrad, pp. 23-48. [In Russian]

Katzenberg, A.M., Weber, A.W. 1999. Stable isotope ecology and paleodiet in the Lake Baikal region of Siberia. Journal of Archaeological Science, 26(6), 651-659

Katzenberg, M.A., Bazaliiskii, V.I., Goriunova, O.I., Savel'ev, N.A., Weber, A.W. 2010. Diet Reconstruction of Prehistoric Hunter-gatherers in the Lake Baikal Region. In: Weber, A.W., Katzenberg, M.A., Schurr, T. (Eds.), Prehistoric Hunter-Gatherers of the Baikal Region, Siberia: Bioarchaeological Studies of Past Lifeways. University of Pennsylvania 
Museum of Archaeology and Anthropology, Philadelphia, pp. 175-192.

Konopatskii, A. K. 1982. Drevnie kul'tury Baikala (o. Ol'khon), Nauka, Novosibirsk. [In Russian]

Kozhov, M.M. 1963. Lake Baikal and its life. W. Junk, The Hague.

Kozhov, M.M. 1972. Ocherki po baikalovedeniiu. Vostochno-Sibirskoe knizhnoe izdatel'stvo, Irkutsk. [in Russian]

Lee, S., Bronk Ramsey, C. 2012. Development and application of the trapezoidal model for archaeological chronologies. Radiocarbon 54(1), 107-122.

Losey, R.J., Bazaliiskii, V.I., Lieverse, A., Waters-Rist, A., Faccia, K., Weber, A.W. 2013. The bearable likeness of being: Ursine remains at the Shamanka II cemetery, Lake Baikal, Siberia. In: Watts, C. (Ed.), Relational Archaeologies. Routledge, London, pp. 65-96.

Losey, R.J., Nomokonova, T., Goriunova, O.I., 2008. Fishing ancient Lake Baikal, Siberia: inferences from the reconstruction of harvested perch (Perca fluviatilis) size. Journal of Archaeological Science 35, 577-590.

Mamonova, N. N. 1973. K voprosu o drevnem naselenii Priangar'ia po paleoantropologicheskim dannym. In: A. P. Smirnov (Ed.), Problemy arkheologii Urala i Sibiri. Moscow: Nauka pp. 18-28. [In Russian]

Mamonova, N. N. 1983. K voprosu o mezhgrupovykh razlichiiakh v neolite Pribaikal'ia. Voprosy antropologii 1, 88-103. [In Russian]

Nomokonova, T.Yu., Goriunova, O.I., Losey, R.J., Savel'ev, N.A. 2011. Ispol'zovanie bukhty Ulan-Khada na ozere Baikal v golotsenie (po faunisticheskim materialam). Arkheologiia, etnografiia i antropologiia Evrazii 2(46), 30-36. [In Russian]

Nomokonova, T., Losey, R.J., Goriunova, O.I., Weber, A.W. 2013. A freshwater old carbon offset in Lake Baikal, Siberia and problems with the radiocarbon dating of archaeological sediments: Evidence from the Sagan-Zaba II site. Quaternary International 290-291, 110-125. [In Russian]

Nomokonova, T.Yu., Losey, R.L., Goriunova, O.I., Novikov, A.G., Weber, A.W. 2015. A 9,000 year history of seal hunting on Lake Baikal, Siberia: the zooarchaeology of Sagan-Zaba II. PLoS One, 10(5), 1-24.

Okladnikov, A.P. 1950 Neolit i bronzovyi vek Pribaikal'ia (chast' I i II). Materialy i issledovaniia po arkheologii SSSR, Vol. 18. Izdatel'stvo Akademii nauk SSSR, Moscow. [In Russian]

Okladnikov, A.P. 1974. Neoliticheskie pamiatniki Angary (ot Shchukino do Bureti), Nauka, Novosibirsk. [In Russian]

Okladnikov, A.P. 1975 Neoliticheskie pamiatniki Srednei Angary (ot ust'ia r. Beloi do Ust'Udy), Nauka, Novosibirsk. [In Russian]

Okladnikov, A.P. 1976 Neoliticheskie pamiatniki Nizhnei Angary (ot Serovo do Bratska). Nauka, Novosibirsk. [In Russian]

Okladnikov, A.P., and Konopatskii, A.K.1974-1975. Hunters for seal on the Baikal Lake in the Stone and Bronze Ages. Folk 16-17:299-308.

Raynard, L.M. Turros, N. 2015. The known, the unknown and the unknowable: weaning times from archaeological bones using nitrogen isotope ratios. Journal of Archaeological Science 53, 618-625.

Reimer, P. et al. 2013. Intcal13 and marine 13 radiocarbon age calibration curves $0-50,000$ years cal BP. Radiocarbon 55 (4), 1869-1887.

Schulting, R.J., Bronk Ramsey, C., Goriunova, O.I., Bazaliiskii, V.I., Weber, A.W. 2104. 
Analysing radiocarbon reservoir offsets with stable isotope data: a case study using paired human and faunal remains from the Cis-Baikal region, Siberia. Radiocarbon 56 (3), 991-1008.

Schulting, R.J., Bronk Ramsey, C., Bazaliiskii, V.I., Weber, A.W. 2105. Highly variable freshwater reservoir offsets found along the Upper Lena watershed, Cis-Baikal, southern Siberia. Radiocarbon 57(4), 1-13.

Shapiro, S. S. and Wilk, M. B. 1965. An analysis of variance test for normality (complete samples). Biometrika 52 (3-4): 591-611.

Shepard B., Goriunova O.I., Novikov A.G., Weber A.W. n.d. A multi-scalar analysis of interconnections among Late Neolithic and Early Bronze Age hunter-gatherers of the Cis-Baikal, Eastern Siberia. Submitted to Quaternary International.

Turkin, G.V., Kharinskii, A.V. 2004. Mogil'niki Shamanka II: K voprosu o khronologii i kul'turnoi prinadlezhnosti pogrebal'nykh kompleksov neolita-bronzovogo veka na Iuzhnom Baikale. Izvestiia Laboratorii drevnikh tekhnologii (Irkutskii GTU) 2, 124-58. [In Russian]

van Klinken, G.J. 1999. Bone collagen quality indicators for palaeodietary and radiocarbon measurements. Journal of Archaeological Science 26(6), 687-95.

Vitkovskii, N. I. 1882. Otchet o raskopkakh mogil kamennogo veka v Irkutskoi gub., na levom beregu Angary, proizvedennykh letom 1881 g. Izvestia VSORGO XIII (1-2), 1-36. [In Russian]

Vitkovskii, N. I. 1889. Sledy kamennogo veka v doline r. Angary. Izvestia VSORGO XX, 1-42. [In Russian]

Ward, G.K. and Wilson, S.R. 1978. Procedures for Comparing and Combining Radiocarbon Age Determinations: A Critique. Archaeometry 20 (1), 19-31.

Waters-Rist, A.L., Bazaliiskii, V.I., Weber, A.W., Katzenberg, M.A. 2011. Infant and child diet in Neolithic hunter-fisher-gatherers from Cis-Baikal, Siberia: intra-long bone stable nitrogen and carbon isotope ratios. American Journal of Physical Anthropology 146, 225-241.

Weber, A.W., Beukens, R., Bazaliiskii, V.I., Goriunova, O.I., Savel'ev, N.A. 2006. Radiocarbon dates from Neolithic and Bronze Age hunter-gatherer cemeteries in the Cis-Baikal region of Siberia. Radiocarbon 48 (3), 1-40.

Weber, A.W., Goriunova, O.I. 2013. Hunter-gatherer migrations, mobility and social relations: A case study from the Bronze Age Baikal region, Siberia. In: Weber, A.W. an. Zvelebil, M., (Eds.), Human bioarchaeology: group identity and individual life histories, Journal of Anthropological Archaeology, Special Issue 32 (6), 330-346.

Weber, A.W., Katzenberg, M.A., Schurr, T. (Eds.). 2010. Prehistoric Hunter-Gatherers of the Baikal Region, Siberia: Bioarchaeological Studies of Past Lifeways. University of Pennsylvania Museum of Archaeology and Anthropology, Philadelphia.

Weber, A., Link, D.W., Goriunova, O.I., Konopatskii, A.K. 1998. Patterns of prehistoric procurement of seal at Lake Baikal: A zooarchaeological contribution to the study of past foraging economies in Siberia. Journal of Archaeological Science 25, 215-227.

Weber, A.W., Link, D.W., Katzenberg, M.A. 2002. Hunter-gatherer culture change and continuity in the Middle Holocene of the Cis-Baikal, Siberia. Journal of Anthropological Archaeology 21, 230-299.

Weber, A.W., Schulting, R.J., Bronk Ramsey, C., Bazaliiskii, V.I., Goriunova, O.I., Berdnikova, N.E. n.d. Chronology of the middle Holocene hunter-gatherers in the Cis-Baikal region 
of Siberia: Corrections based on examination of the freshwater reservoir effect. Submitted to Quaternary International.

Weber, A.W., White, D., Bazaliiskii, V.I., Goriunova, O.I., Savel'ev, N.A., Katzenberg, M.A. 2011. Hunter-gatherer foraging ranges, migrations, and travel in the middle Holocene. Baikal region of Siberia: Insights from carbon and nitrogen stable isotope signatures Journal of Anthropological Archaeology 30, 523-548.

Yoshii, K., Melnik, N.G., Timoshkin, O.A., Bondarenko, N.A., Anoshko, P.N., Yoshioka, T., Wada, E. 1999. Stable isotope analyses of the pelagic food web in Lake Baikal. Limnology and Oceanography 44(3), 502-11. 


\section{FIGURES}

Figure 1. Location of Shamanka II and other relevant Early Neolithic cemeteries referenced in the paper.

Figure 2. Map of Shamanka II.

Figure 3. Chronology of Early Neolithic Shamanka II, Angara valley, and Lokomotiv based on Bayesian modeling in $\mathrm{OxCal}$ (4.2.4) using the trapezoidal distribution:

(a) Boundaries;

(b) Intervals.

Figure 4. Shamanka II, modelled mean HPD cal BP dates:

(a) NW Cluster, SE Cluster, and S Sector;

(b) Burials from rows of graves and burials from scattered graves.

Figure 5. Shamanka II, modelled mean HPD cal BP dates for:

(a) Sex and main age groups;

(b) Individuals interred in graves with single burials;

(c) Individuals interred in graves with multiple burials.

Figure 6. Stable isotope results for Early Neolithic Shamanka II, Early Neolithic Angara valley and Early Bronze Age game-fish-seal diet group from the Little Sea micro-region.

Figure 7. Modelled mean HPD cal BP dates by $\delta^{15} \mathrm{~N}$ or $\delta^{13} \mathrm{C}$ measurements for Shamanka II (Table 1) and Early Neolithic burials in the Angara valley (Weber et al., in press).

Figure 8. Shamanka II stable isotope results by main temporal and spatial units:

(a) Phases;

(b) Clusters.

Figure 9. Shamanka II, Phase 1, stable isotope results by:

(a) Clusters and grave formation;

(b) Clusters and skeletal sex.

\section{TABLES}

Table 1. Archaeological data, corrected radiocarbon dates and results of the Bayesian analysis using the trapezium distribution model for the Early Neolithic component of the Shamanka II cemetery. Records are grouped by phase and sorted by corrected date BP.

Table 2. Summary of Bayesian chronological modelling for Early Neolithic Shamanka II, Angara valley and Lokomotiv.

Table 3. Shamanka II: Descriptive statistics for stable isotope measurements for relevant units of analysis.

Table 4. Descriptive statistics for stable isotope measurement for the Early Neolithic burials from Shamanka II, the Angara valley and Early Bronze Age individuals with the Game-Fish-Diet from the Little Sea micro-region.

Table 5. Summary of PCC analysis for Shamanka II and the Angara valley.

\section{SUPPLEMENTS}

Supplement 1. Geochemical data for the Early Neolithic component of the Shamanka II cemetery from the Oxford Radiocarbon Accelerator Unit, University of Oxford, UK. Records are sorted by Master_ID numbers. 
Supplement 2. OxCal 4.2.4 input file for Bayesian analysis for the Early Neolithic Shamanka II, Angara valley and Lokomotiv cemeteries using the default uniform distribution model. Cases are sorted by the corrected ${ }^{14} \mathrm{C}$ dates BP.

Supplement 3. OxCal 4.2.4 input file for Bayesian analysis for the Early Neolithic Shamanka II, Angara valley and Lokomotiv cemeteries using the trapezoidal distribution model. Cases are sorted by the corrected ${ }^{14} \mathrm{C}$ dates $\mathrm{BP}$. 